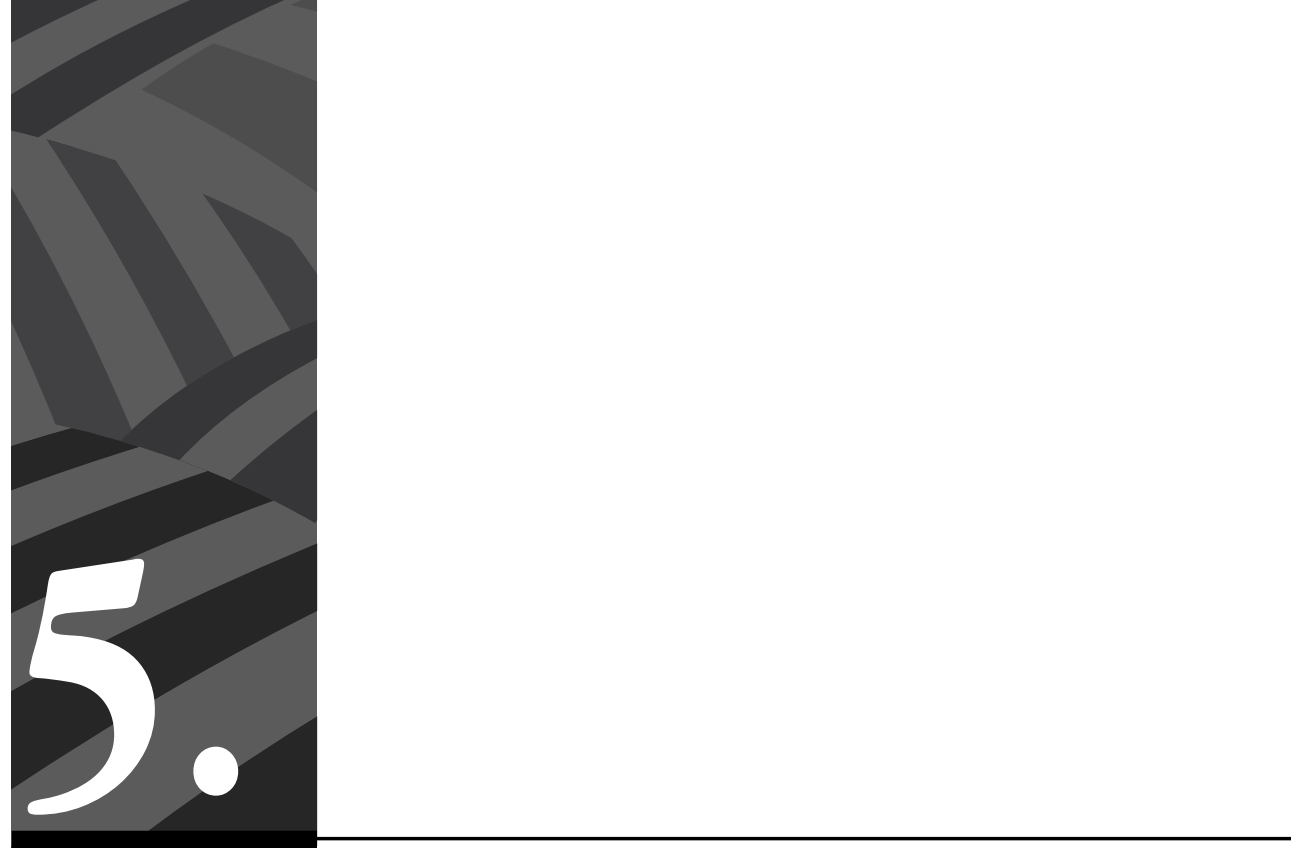

Entre los márgenes y el uso estratégico: territorialidades en disputa en el Macizo caucano 


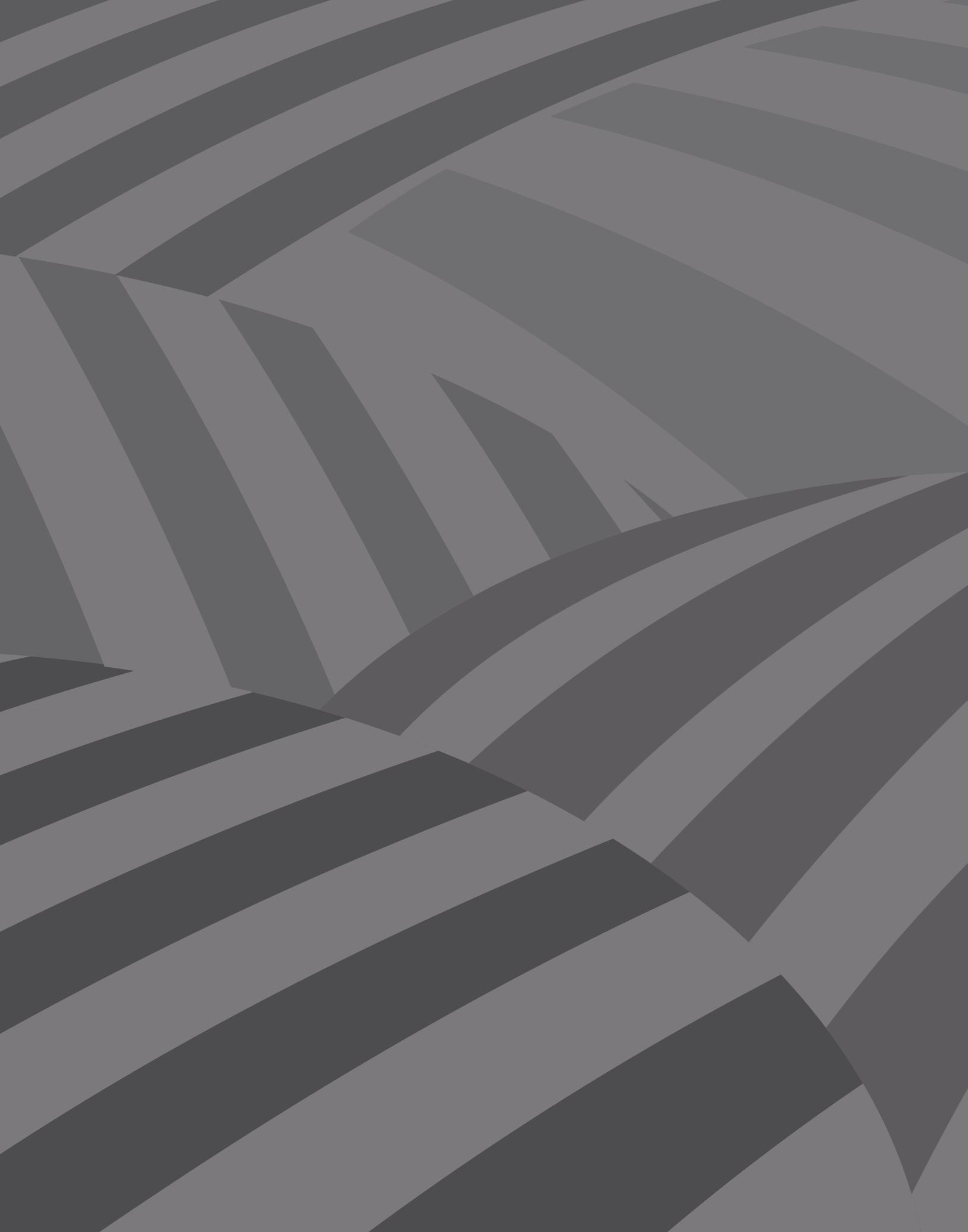




\section{Entre los márgenes y el uso estratégico: territorialidades en disputa en el Macizo caucano*}

Por María Catalina Gómez Dueñas ${ }^{1}$

\section{Introducción}

El presente texto aborda la caracterización del Macizo caucano con el propósito de dar a conocer las distintas condiciones materiales en las que se generan tensiones alrededor de la propiedad y uso de la tierra. Se parte de la estructura actual de la propiedad rural en el Cauca para así ofrecer un panorama general que permita localizar la región. Esta aproximación nos permite comprender el sentido y esencia de ciertos lugares en disputa, e identificar una perspectiva a través de la reivindicación de derechos diferenciales en contextos que incluyen y trascienden asuntos culturales. Por un lado, el sentido referido anteriormente se identifica a partir de las reivindicaciones y denuncias de algunas organizaciones sociales presentes en el territorio; mientras que las condiciones materiales resultan de una revisión sobre las características geográficas, económicas y sociales que ofrecen distintos acervos bibliográficos.

* Artículo recibido en julio de 2015

Artículo aprobado en octubre de 2015

Socióloga egresada de la Universidad del Valle, Cali. Maestra en Ciencias Sociales de la Flacso, sede académica de México. Ha sido profesora en el Departamento de Estudios Sociales de la Universidad Icesi en Cali y actualmente trabaja como colaboradora en la línea de investigación sobre desarrollo rural y ordenamiento territorial en el Instituto de Estudios Interculturales de la Pontificia Universidad Javeriana de Cali. 
Al Macizo colombiano se le conoce como nudo colombiano o nudo de Almaguer y, como señala Torres (2001), geomorfológicamente se ubica en la unión entre las Cordilleras Central y Oriental. Esta unión se da a través de las aguas que alimenta a los ríos Magdalena y Caquetá, ubicadas en el eslabón de Santa Rosa donde se comunican los departamentos del Cauca y Valle del Cauca, así como los de Caquetá y el Amazonas. Es denominada como la estrella fluvial colombiana ya que en esta región nacen cuatro ríos de gran importancia: Caquetá, Patía, Magdalena y Cauca. El Macizo abarca 362400 hectáreas, distribuidas entre los departamentos del Cauca, en los municipios de Sotará, Rosas, La Sierra, La Vega, Almaguer, San Sebastián, Santa Rosa y Bolívar; y del Huila, en San José de Isnos, La Plata, Salado Blanco y San Agustín. No obstante, distintas investigaciones ofrecen límites político-administrativos más amplios, donde se incluyen municipios pertenecientes a los departamentos de Caquetá, Nariño, Putumayo y Tolima² . La pluralidad de delimitaciones espaciales para la región ha sido fundamental para que el Instituto de Estudios Interculturales, a partir de las referencias que ofrece el IGAC (2009), y de su acervo investigativo, estudie los municipios de Almaguer, La Vega, La Sierra, Rosas y Sotará como parte importante de la caracterización del Macizo caucano.

Este Macizo es una región de uso estratégico para distintos actores sociales en diferentes momentos de la historia política y económica colombiana. Esta propuesta implica que dichos usos se dan en medio de relaciones de fuerza y presencia asimétricas, donde las comunidades y sus pobladores han estado en condiciones de subordinación y despojo. Esta condición de vulnerabilidad solo es posible identificarla y analizarla en el marco de un modelo económico y de desarrollo que privilegia prácticas tales como la extracción de minerales a gran escala y la explotación y contaminación de los recursos naturales. De este modo se afecta la economía local y regional, y en esta misma dirección, la seguridad alimentaria de la región.

2 Al respecto ver Aldana (1998); Zambrano (2001) y Nates (2002). 
Lo anterior se ve reforzado por una presencia estatal predominantemente militar, así como por economías ilegales (ciertas prácticas mineras y cultivos ilícitos) impulsadas y sostenidas por actores armados también ilegales. En este sentido, los conflictos por el uso de la tierra son fundamentales a la hora de comprender la estructura de la propiedad. En el Macizo caucano hay muchos propietarios con poca tierra y a su vez pocos con extensas cantidades. En este contexto, las disputas no solo se dan entre las comunidades organizadas (campesinas, indígenas y afro) y el Estado, las empresas privadas, la guerrilla o los paramilitares; también se dan entre ellas mismas.

Para comprender los factores y problemáticas hasta ahora mencionados, el presente artículo se encuentra dividido en cuatro partes. La primera ofrece elementos geográficos, históricos, demográficos y territoriales que permiten comprender al Macizo caucano como una región. La segunda identifica los elementos centrales de una economía de autoabastecimiento y comercio local y regional, enlazada con la economía ilegal de la coca y la amapola, y con la entrada reciente de la minería a gran escala. En tercer lugar se presentan hitos sociales en clave de características territoriales que dan cuenta de la ausencia y presencia del Estado, así como de la movilización social organizada. Este aspecto se complementa con algunas reflexiones en torno a los impactos del conflicto armado que se vive en la zona. Por último, se ofrece una perspectiva final donde se articulan los anteriores elementos y se dejan algunas preguntas para futuras investigaciones en la materia.

La tesis central del presente análisis está sustentada en la idea de una región habitada por actores sociales que ejercen resistencias en medio de condicionamientos estructurales económicos y políticos de carácter nacional y global. En este contexto la estructura y uso de la tierra resultan ser bienes en disputa, que implica conflictos de distinta naturaleza con un modelo productivo y de desarrollo que desconoce las necesidades y reivindicaciones de sus pobladores. 


\section{El Macizo caucano como región: breve caracterización}

El Macizo caucano corresponde al 5,3\% del área total del departamento del Cauca (162.100,92 ha). A nivel interno, los municipios de La Vega y Sotará circunscriben la mayoría del territorio (31,9\% y 31,6\% respectivamente), a los cuales le sigue Almaguer con un 15,1\%, La Sierra con el 12,7\% del total y, por último, el 8,8\% perteneciente al municipio de Rosas. En esta región es posible encontrar terrenos planos y montañosos, alturas que oscilan entre los 800 y 4600 m.s.n.m y temperaturas que van de los 6 a los 22 grados centígrados. Según informe de la Cancillería (2005), esta zona es reconocida por la UNESCO como Reserva de Biósfera desde 1979; esto se debe a que es uno de los sitios con mayor biodiversidad en el mundo y de los principales en la producción de agua. Según informes del Instituto de Estudios Interculturales (IEI), y estudios adelantados por Aldana (1998) y Maimán et al (2013), en esta zona no solo se encuentran climas y especies variados, sino también minerales como oro y petróleo. Estas condiciones geofísicas son fundamentales para entender la estructura de la propiedad en la región, pues dan cuenta de la riqueza ambiental que se encuentra estrechamente ligada con los diversos usos que hacen los actores sociales presentes en el territorio. Al respecto, de acuerdo con el IGAC, la vocación del suelo es principalmente agroforestal (71 057 ha), también agrícola (16 287 ha) y de conservación (14 764 ha), además hay usos forestales y de ganadería pero en mucha menor medida. Sin embrago, como se verá más adelante los usos son distintos a la vocación del suelo, lo que lleva a sobre o subutilización del mismo.

Esta región también se configura a partir de distintos elementos históricos, políticos y sociales. En este sentido, la investigación de Luz Ángela Herrera (2003) propone que es imprescindible “comprender los conflictos sociales (...) [que se] expresan [en] formas históricas de apropiación del territorio por el control de recursos económicos y políticos" (49). Esta aclaración es oportuna al momento de estudiar este territorio 
como una región que tiene la capacidad de reconocer a sí misma. En este sentido, un ejercicio de regionalización no se refiere exclusivamente a factores biofísicos y/o geológicos compartidos, también requiere incluir elementos definidos por los usos, prácticas, significaciones e identificaciones sociales de quienes allí convergen. Así, el Macizo colombiano es caracterizado por Herrera como una región que comparte particularidades propias del departamento del Cauca; y, en una clave socio-histórica, propone que este territorio hizo parte del escenario en el cual se desarrollaron procesos de consolidación y diferenciación entre las ciudades de Popayán y Cali desde el periodo colonial hasta inicios del siglo $\mathrm{XX}^{3}$. La importancia de este señalamiento radica en que permite comprender ambas ciudades, y sus regiones circundantes, como unidades que comparten un pasado de valores propios del sistema productivo de hacienda, la minería, el esclavismo y la encomienda. Pero, además, las características mencionadas permiten distinguir las disputas políticas y de élites en torno a la propiedad y administración de la tierra, así como a la implantación de la agroindustria.

Al respecto, es importante mencionar que la economía minera jugó un papel crucial en la fundación de ciudades -es el caso de Almaguer en 1551-, así como en los procesos de poblamiento de zonas inhóspitas por parte de población indígena y negra, que no se sometía a las formas de explotación de la mano de obra que esta implicaba. En dicha vía, la minería también aportó en el proceso de expansión de las haciendas, pues alrededor de aquellas se consolidaron asentamientos que luego serían pueblos importantes para el comercio de productos agrícolas y para la conexión con las minas. Además, hacia finales del siglo XVIII e inicio del XIX, dichos asentamientos fueron cuna y aporte para los procesos de cambio social que viviría el país, fundamentados en el cuestionamiento y debilitamiento de la hacienda y el esclavismo como estructura social y productiva.

En el marco de las distinciones que proponen los variados estudios sobre el territorio denominado como suroccidente colombiano. 
A lo largo del siglo XX, otro elemento característico de la región fue la preponderancia de los partidos políticos en los ejercicios de mediación entre el Estado y los grupos sociales dominantes, en un contexto de fragmentación de poderes locales, regionales y nacionales. No obstante, el debilitamiento de dichos partidos en la segunda mitad del siglo también es un hecho significativo que da cuenta de ciertas formas de participación política distintas a la electoral. En el territorio del Macizo caucano, los municipios de Almaguer y Bolívar fueron escenarios privilegiados para la construcción de dichas mediaciones; privilegio que provenía de terratenientes, notables, clérigos y comerciantes.

Otra característica que identifica Herrera (2003) es el papel de los pobladores que resisten a los distintos órdenes dominantes, tanto por la vía armada como por la protesta social. Dicha resistencia se daba bien en contra del esclavismo, racismo y estructura señorial de la sociedad -elementos propios de la época colonial y heredados en distintos sustratos sociales a lo largo del tiempo-, como en la búsqueda de reconocimientos diferenciales. Respecto a esto último, debe anotarse que se daban en términos de los derechos económicos, políticos y sociales leídos en una clave étnica.

Finalmente, hay dos características fundamentales para dar cuenta de los procesos organizativos recientes en el Cauca y que constituyen igualmente región. La primera de estas se encuentra vinculada con el debilitamiento de los partidos tradicionales y el surgimiento y fortalecimiento de otro tipo de organizaciones en la segunda mitad del siglo XX, las cuales continúan actualmente en luchas por la propiedad y uso de la tierra. Una muestra de esto es el caso de la Asociación Nacional de Usuarios Campesinos (ANUC) y el Comité Regional Indígena del Cauca (CRIC), quienes en los años sesenta y setenta recuperaron reivindicaciones de carácter identitario de las comunidades rurales. Como ejemplo de lo anterior existe un proceso que se encuentra en los poderes ejecutivos y legislativos departamentales: la gobernación del Cauca, ganada por el Partido Liberal Colombiano en los periodos correspondientes a 
1994 y 1997, quedó en el 2000 en manos de la Alianza Social Indígena en cabeza de Floro Tunubalá. Este hecho tuvo un estrecho vínculo con los procesos de movilización social y organizativos de sectores campesinos, indígenas, afrodescendientes, y en general de los habitantes de la ruralidad caucana (MOE, 2010) ${ }^{4}$.

La segunda característica tiene que ver con las comunidades circundantes y vecinas de la región, y con las problemáticas comunes en torno a la violación de Derechos Humanos, la presencia de cultivos ilícitos y los modelos de desarrollo implementados por parte de los gobiernos nacionales. Estos temas son profundizados a continuación en este artículo, pues hacen parte de las razones que permiten pensar al Macizo caucano como una región que históricamente ha hecho parte de la construcción del Estado y la Nación desde la marginalidad. Además, al constituirse actualmente como un territorio estratégico, este territorio no deja de tener características propias de una región con fuertes inequidades pero enormes potencialidades para consolidar un modelo económico extractivista y de desposesión. En este contexto, tanto los conflictos interétnicos por la propiedad de la tierra, como los encuentros en procesos de resistencia que cuestionan el sistema político-económico, resultan ser espacios para repensar la naturaleza multicultural del territorio, sus alcances y sus limitaciones.

4 No obstante, para los siguientes periodos electorales retornaron los partidos tradicionales: en el 2003 la gobernación fue del Partido Conservador y en el 2004 del Liberal. Aunque, en el año 2007 fue elegido el representante del Movimiento Nacional Afrocolombiano, "Afro”, sin que esta fuera una candidatura consensuada por la totalidad de los miembro del movimiento, ya que para algunos representaba a la clase política tradicional (MOE, 2010). En el año 2011 retornó un partido no tradicional, la Alianza Social Independiente, y en el 2015 volvió el Partido Liberal. Este tipo de presencia en el espectro político también se ve reflejada en la composición de la Asamblea Departamental, a lo lardo de diez años (de 1997 a 2007), donde predominan los partidos Liberal y Conservador. Sin embargo, la presencia de las organizaciones sociales de la ruralidad se ha mantenido y constituyen interlocutores que van más allá de la dimensión político-electoral. 


\section{Elementos demográficos: actualidad y tendencias}

De acuerdo con las proyecciones de población del DANE, entre los años de 1985 y 2015 la población del Macizo caucano presentó una tendencia al aumento, pasando de 74152 habitantes a 107 719. Los municipios de La Vega, Rosas y Sotará tuvieron una tendencia similar aunque no tan pronunciada, mientras que la población de Almaguer aumentó de forma muy leve y en La Sierra disminuyó. Para el año 2015 la región representa el 7,8\% de la población del departamento del Cauca: el municipio de La Vega acumula casi la mitad de su población (42,3\%), posteriormente Almaguer $(19,7 \%)$, seguido por Sotará $(15,8 \%)$, Rosas $(12,3 \%)$ y La Sierra $(9,9 \%)$. Vale señalar que esta distribución ha sido similar en los últimos 30 años.

Respecto a la distribución de la población según su ubicación en las cabeceras municipales, el Macizo caucano mantienen la relación del departamento del Cauca al año 2015, donde el 60,3\% de sus habitantes se encuentran en zonas rurales y el 39,7\% está en las cabeceras. La región tiene proporciones ubicadas por encima del promedio departamental, de manera que el 92,2\% de la población se encuentra en la zona rural y el restante $7,8 \%$ en las cabeceras. Por otro lado, el DANE reporta que las zonas rurales de la región han aumentado su población desde 1985 y hasta la actualidad, ya que para la década de los ochenta acumulaban el $88,9 \%$ de la población y las cabeceras el 11,1\%. Esta tendencia se mantiene a nivel municipal, exceptuando el caso de La Sierra, ya que en este municipio se da un aumento de la población ubicada en la cabecera. Por otra parte, al observar la distribución de la población según sexo, se encuentra que la región reproduce el patrón del Cauca, es decir que suma más hombres que mujeres 50,7\% y 49,3\%, respectivamente.

Finalmente, la distribución de los habitantes indígenas y afro varía: mientras que en el Cauca estas poblaciones tienen valores similares $(21,5 \%$ y $22,2 \%$ respectivamente), en la región del Macizo hay mucha más presencia indígena (con una relación de $25,6 \%$ a 1,6\% respectivamente). 
Este tipo de distribución se mantiene a nivel municipal, en algunos casos con acumulaciones inferiores de afros. Un caso es el de la zona de Almaguer, La Vega y Sotará; mientras que en Rosas y La Sierra las acumulaciones son superiores a la regional. Adicionalmente, debe mencionarse que el municipio de Sotará tiene un 46,7\% de población indígena, lo que posiblemente se encuentra relacionado con su cercanía a la zona oriente del departamento. De manera que, para el año 2015, la mayoría de la población de la región es caracterizada mediante la categoría censal de "pertenencia a ninguna de las anteriores opciones" (72,8\%); no obstante, en el Cauca la proporción es inferior a la de la región (56,3\%) y sus municipios ${ }^{5}$.

En términos de las figuras de ordenamiento territorial rural, en el Macizo caucano se encuentran resguardos indígenas constituidos, también en solicitud, así como asentamientos coloniales en clarificación de comunidades Yanacona y Nasa. También es posible identificar Consejos Comunitarios Afros, que, a pesar de no constituir una figura territorial, son el ente institucional mediante el cual se tramita la solicitud para una titulación colectiva del territorio. Así mismo, existe la solicitud de constitución de una Zona de Reserva Campesina y de Territorios Agroalimentarios. De acuerdo con la última información proporcionada por el Incoder (2015), en la región existen tres resguardos indígenas de reciente constitución: dos de la comunidad Yanacona, ubicados en el municipio de la Sierra (Resguardo El oso) y en el municipio de La Vega (Resguardo Guachicono); y un tercero perteneciente a la comunidad Nasa (Resguardo de El Peñón), localizado en el municipio de Sotará . En dichos Resguardos el número de familias presentes a 2015 es de 80, 15.5 y 47 respectivamente. Además, existen cuatro solicitudes en proceso para la constitución de nuevos resguardos: Frontino, Yanacona del

Ver Anexo 1

Resguardos creados mediante las siguientes resoluciones: El Oso, resolución 294 del 29 de noviembre de 2012; Guachicono, resolución 177 del 3 de septiembre de 2009 y El Peñón, resolución 287 del 28 de agosto de 2012. 
Moral y Puerta del Macizo, en el municipio de La Sierra, y el resguardo Santa Bárbara en La Vega. Adicionalmente, hay tres resguardos coloniales en clarificación: Caquiona, ubicado en Almaguer, Pancitará, en el municipio de La Vega, y Río Blanco, en Sotará. Estos ocupan el 17,7\% del territorio (28 690,36 ha) correspondiente a la región del Macizo caucano ${ }^{7}$.

\section{Tabla 1. Distribuciones de áreas (ha) de los resguardos indígenas en el Macizo caucano}

\begin{tabular}{|c|c|c|c|c|}
\hline \multirow{2}{*}{ Municipio } & \multicolumn{4}{|c|}{ Resguardos indígenas } \\
\cline { 2 - 5 } & Área & $\begin{array}{c}\text { Área dentro del } \\
\text { municipio (\%) }\end{array}$ & $\begin{array}{c}\text { Área dentro de } \\
\text { la región (\%) }\end{array}$ & $\begin{array}{c}\text { Área de } \\
\text { resguardos (\%) }\end{array}$ \\
\hline Almaguer & 6368,32 & $26.0 \%$ & $3.9 \%$ & $22.2 \%$ \\
\hline La Sierra & 1274728 & $0.6 \%$ & $0.1 \%$ & $0.4 \%$ \\
\hline La Vega & 10440.88 & $20.2 \%$ & $6.4 \%$ & $36.4 \%$ \\
\hline Rosas & - & $0.0 \%$ & $0.0 \%$ & $0.0 \%$ \\
\hline $\begin{array}{c}\text { Sotará } \\
\text { (Paispamba) }\end{array}$ & 11753.68 & $23.0 \%$ & $7.3 \%$ & $41.0 \%$ \\
\hline $\begin{array}{c}\text { Región } \\
\text { Macizo } \\
\text { caucano }\end{array}$ & 28690.3565 & & $17.7 \%$ & $100.0 \%$ \\
\hline Cauca & 3060887.52 & \multicolumn{4}{|l}{} \\
\hline
\end{tabular}

Fuente: elaboración del IEI a partir de información del Instituto Colombiano de Desarrollo Rural, Incoder (2015)

Como bien se puede identificar en la tabla, en tres de los cinco municipios de la región los resguardos acumulan aproximadamente el $25 \%$ del total del territorio municipal; $26 \%$ en el caso de Almaguer, $23 \%$ en Sotará y $20,2 \%$ en La Vega. Por su parte, en el municipio de La Sierra suman un 0,6\% y en el de Rosas no se reporta información. Esta concentración de hectáreas engloba tanto resguardos constituidos, como

Ver Tabla 1. Este cálculo incluye los valores correspondientes a los resguardos indígenas constituidos, en solicitud y en clarificación. 
solicitudes de constitución y/o ampliación, y resguardos coloniales o en clarificación. Debe tenerse en cuenta que, tanto a nivel municipal como regional, los resguardos indígenas coloniales -en clarificación- son los que más área tienen. En lo que refiere a titulaciones colectivas para comunidades negra, como ya se mencionó, no hay ninguna constituida hasta el momento; sin embargo ya hay una inscrita en el municipio de La Sierra y otra en Rosas. Estas inscripciones se realizaron ante la Alcaldía el Consejo Comunitario de Negritudes, Zona Occidente (Afrociso) y el Consejo Comunitario Pan de Azúcar respectivamente. También hay una solicitud de constitución para una Zona de Reserva Campesina en el municipio de La Vega, con un área de 27.717,22 hectáreas. Además, el IEI documentó en el 2015aspiraciones para establecer territorios agroalimentarios en Sotará, Almaguer y Rosas. Así mismo, hay aspiraciones territoriales por parte de la ANUC Cauca.

La presencia de estas distintas poblaciones en el territorio, así como el predominio de resguardos indígenas frente a otro tipo de figuras de ordenamiento territorial, son características fundamentales de los conflictos interculturales en el territorio; conflictos que se refieren a la estructura de la propiedad y su uso. En particular, organizaciones como los Consejos Comunitarios de la Cuenca Alta de Río Patía (Corpoafro), el Proceso de Unidad Popular del Suroccidente Colombiano (Pupsoc) y la Asociación Nacional de Usuarios Campesinos (Anuc), dan cuenta de disputas entre comunidades indígenas, afro y campesinas organizadas por la propiedad de predios. Las fincas en disputa son reclamadas como propias ya sea apelando a la actual presencia poblacional de cada una de las comunidades en el territorio, o a la presencia ancestral -en algunos casos desplazada debido al proceso de colonización o al conflicto armado-. Este tipo de conflictos también implican disputas con Cabildos indígenas debido a la administración de la salud o la educación, pues en diversos casos no todos los habitantes de los resguardos se reconocen como indígenas y hacen parte de procesos organizativos campesinos. 
La diversidad demográfica de la región constituye procesos de resistencia articulada en distintos momentos de la historia, pero a su vez también implica la configuración de conflictos. El tipo de conflictividad hasta el momento referenciada, y relacionado a la tenencia de tierras, da cuenta de la existencia de condiciones jurídicas que privilegian al sujeto afro e indígena frente al campesino, al momento de adjudicar predios y reconocer derechos. Este recurso constitucional, que ha permitido el reconocimiento de condiciones de vulnerabilidad y despojo de comunidades étnicas, a su vez ha exacerbado los conflictos con otro tipo de pobladores. Es este el caso de la comunidad campesina, la cual no se ve acogida por formas de reconocimiento, pero que también habitan, construyen y recuperan como propio el territorio de esta región. Vale preguntarse, ¿en qué condiciones materiales se dan estos conflictos?, ¿con cuánta tierra se dispone para satisfacer las necesidades de cada población?, ¿en medio de qué modelo económico pueden aprovechar o no las tierras estas organizaciones reclamantes? Los siguientes acápites buscan dar respuesta a estos cuestionamientos, y para ello se unen aspectos tales como los momentos de cambio social que han potenciado el uso estratégico actual del territorio, la presencia de actores sociales como las empresas privadas, el Estado y los actores armados ilegales. La conjunción de estos factores se realiza debido a que esto permite analizar con mayor agudeza las condiciones en las que los procesos organizativos de la sociedad civil rural entran en disputan.

\section{La dimensión económica: actividades productivas y economías ilegales}

Actualmente el 45,3\% del suelo del Macizo caucano se encuentra clasificado como páramo, el 25,9\% como zona de reserva forestal y el $21,1 \%$ se ha adjudicado para títulos mineros, lo que se relaciona indiscutiblemente con la biodiversidad que caracteriza a la zona ${ }^{8}$. Además,

$8 \quad$ Ver Tabla 2. 
en el municipio de Sotará hay un 3,0\% del suelo cultivado con pino eucalipto y un $0,03 \%$ del total regional pertenece a reservas naturales; por lo tanto, el restante $4,6 \%$ del territorio debe repartirse para ser utilizado como zona de vivienda, de cultivo y/o para la ganadería. Así pues, es posible proponer que los conflictos interétnicos mencionados se dan en medio de escasez de tierra para el cultivo.

Tabla 2. Participación de los usos del suelo en el Macizo caucano

\begin{tabular}{|l|c|c|c|}
\hline \multicolumn{1}{|c|}{ Municipio } & Área (h) & Área \% & Fuentes \\
\hline Páramos & 73447.13842 & $45.31 \%$ & IGAC (2012) \\
\hline Reservas Naturales & 513814 & $0.03 \%$ & IGAC (2012) \\
\hline $\begin{array}{l}\text { Zonas de Reserva } \\
\text { Forestal }\end{array}$ & 41927.42473 & $25.9 \%$ & IGAC (2012) \\
\hline Títulos Mineros & 34278.78855 & $21.1 \%$ & ANM (2014) \\
\hline Pino & 4942.48583 & $3.0 \%$ & (IGAC 2012) \\
\hline $\begin{array}{l}\text { Total (áreas no } \\
\text { cultivables) }\end{array}$ & 154647.2189 & $95.4 \%$ & \\
\hline $\begin{array}{l}\text { Región Macizo } \\
\text { caucano }\end{array}$ & 162100.92 & $100.0 \%$ & \\
\hline
\end{tabular}

Fuente: Elaboración IEI, distintas fuentes

Es fundamental señalar que del total de la propiedad rural el 73,02\% de los predios se clasifica como microfundio (3 ha o menos) y suman únicamente el $12,32 \%$ de la superficie de la tierra, luego se encuentra el minifundio (entre 3 y $10 \mathrm{ha}$ ) con el $19,21 \%$ de los predios y el 23,41\% de la superficie de la tierra; de manera que, entre estas dos categorías prediales se ubica el $36 \%$ de la tierra. Por otra parte, la pequeña/mediana propiedad (entre 20 y 50 ha) tiene el 2,73\% de los predios que suman el 22,39\% de la superficie mencionada, mientras que el 0,11\% son predios grandes (más de $200 \mathrm{ha}$ ) que suman el $21,78 \%$ de dicha superficie; entonces, ambas categorías prediales acumulan el 44,17\% de la tierra ${ }^{9}$. Estos datos indican que en la región del Macizo caucano las m 
superficies más grandes están distribuidas en pocas. En este contexto, las solicitudes de titulación que hacen las distintas organizaciones sociales ya mencionadas no constituyen grandes cantidades, además debe recordarse que predomina la adjudicación de superficie a las comunidades indígenas.

\section{Gráfico 1.}

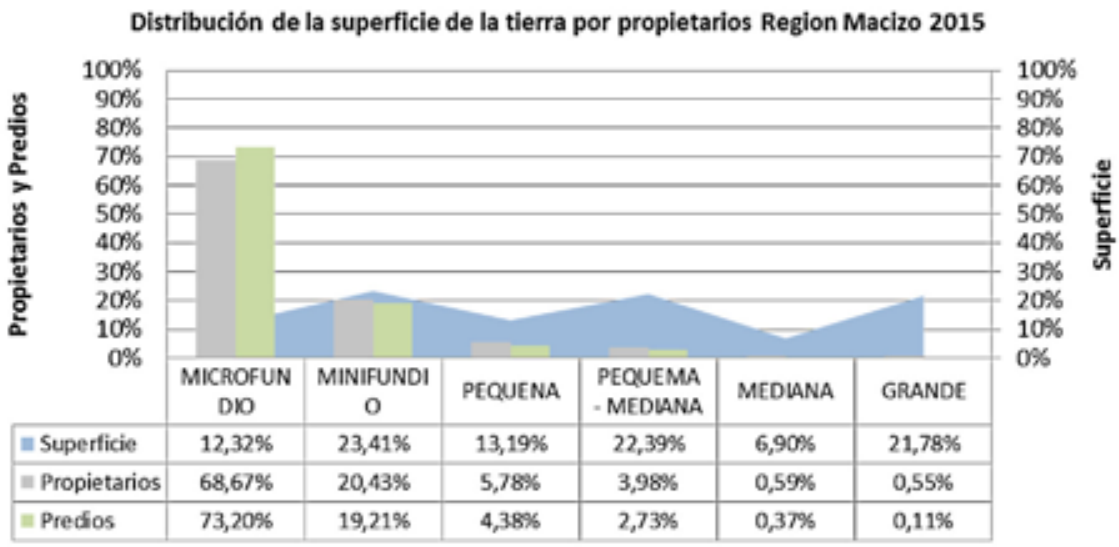

Fuente: Elaboración IEI, Registro Uno, IGAC

Respecto al uso del suelo, el estudio del IEI (2013) sobre la UAF en el departamento del Cauca indica que los municipios correspondientes al Macizo caucano se componen de vegetación secundaría, pastos y áreas agrícolas heterogéneas, donde los principales productos agrícolas son la caña panelera, el maíz, la cebolla, el fríjol, la papa, el café tradicional, el plátano, la yuca, la piña, la papaya, la fresa y el mango. También se encuentran cultivos permanentes y transitorios de distinto tipo, y hay huertas para la subsistencia; por su lado, el tema del ganado se da de manera extensiva para la producción de leche. De acuerdo con la información proporcionada por la Secretaría de Desarrollo Agropecuario y Fomento Económico del departamento del Cauca -sobre el área sembrada entre los años 2005 y 2013 en el Macizo caucano-, el café acumuló un 
poco más de la mitad de dicha área, con un aumento significativo entre el 2011 y 2012. En segundo lugar se ubicó la caña panelera, que tuvo una tendencia al aumento, el plátano también tuvo una participación importante pero con una tendencia a la disminución. Finalmente, se encuentra la yuca, la cual tiene una tendencia estable en el periodo señalado pero sin llegar a superar el 5\% del área sembrada.

El mismo estudio del IEI indica que los productos más competitivos de los municipios de la región son: el ganado, la acacia de la parte forestal, la papa, el fríjol, la caña y la papaya. Además, menciona que en la zona se encuentra el $4 \%$ de las empresas del sector primario del departamento y el $4 \%$ de las del sector secundario. También se da cuenta en este informe de una producción agrícola de subsistencia, caracterizada por llevarse a cabo en pequeñas extensiones de tierra, con poca o nula asistencia técnica, con un uso de la fuerza de trabajo familiar y mínima inversión de capital. Estos elementos posibilitan la identificación de algunos excedentes comerciales -principalmente de la producción de café-, con una alta presencia de intermediación para la comercialización regional, una contratación de mano de obra para los periodos de siembra y cosecha, y algunas asesorías por parte de la Federación de Cafeteros de Colombia, la UMATA y la Corporación Autónoma Regional del Cauca.

Para el primer decenio del siglo XXI estudios como lo de Del Cairo (s.f.) dan cuenta de municipios donde hay escasez de agua potable y benéfica para el cultivo, así como de esterilidad en la tierra ${ }^{10}$. Parte de estas problemáticas se encuentran estrechamente vinculadas con los procesos de colonización de distintas épocas, la extracción maderera en algunas zonas, el uso de químicos en las plantaciones -glifosato para la erradicación de los cultivos ilícitos- y en las actividades mineras -mercurio y cianuro-. Pero no debe dejarse de lado la influencia que sobre esta zona tuvo la llegada de los cultivos de coca y amapola, así

10 Sobre el tema también revisar Gómez (2013); Maimán et al (2013) y Tocancipá (s.f.). 
como la minería a gran escala, ya que desde su aparición dinamizaron la economía de la región.

\section{La coca y amapola}

Entre los años sesenta y ochenta, el auge de los cultivos de la hoja de coca para usos ilícitos es un hito económico y social fundamental para entender la estructura de la propiedad de la tierra rural, pues llevó a las modificaciones de ciertas prácticas agrícolas y sociales de la población del Macizo. En la investigación de Torres y Joaqui (1995), sobre el municipio de Bolívar ${ }^{11}$, se propone que el problema moderno del comercio de la coca puede tener su inicio en la expedición del Decreto 896 de 1947. Frente a este no solo se pronunciaron los cultivadores de la región, también terratenientes y políticos que los apoyaban, lo que evidencia la fuerza y presencia del cultivo en el territorio. Para los años sesenta se reporta gente comprando la hoja de coca a mejores precios de lo habitual, sin conocer el paradero y uso de la misma. En esta investigación, además, se vincula la llegada de los Cuerpos de Paz a la zona, con el contacto y conocimiento de los cultivadores sobre el valor que la hoja tiene para la producción de la cocaína y su comercio a nivel mundial.

Para la primera mitad de los setenta se evidenció la inyección de capital que trajo este tipo de producción, en comparación con los bajos ingresos que generaban los cultivos de maíz, yuca, caña, maní o café. De manera que la acumulación de dinero y la compra de objetos de valor fue pública, como lo fue también el aumento de laboratorios para el procesamiento de la hoja y el alza en la mano de obra para la siembra, el cultivo, procesamiento y vigilancia de las plantaciones; así como también en el transporte y comercialización de la coca procesada. Hacia finales esa década empiezan a llegar negociantes y nuevos pobladores,

11 Que a pesar de no pertenecer a la región de estudio puede ser tenido como referencia dada la cercanía y similitudes con los demás municipios que la componen. 
provenientes todos de ciudades capitales como Cali, Bogotá y Medellín. Esta migración repercutió en el inicio de mercados de armas y bebidas alcohólicas extranjeras -como el whisky- y consolidó al decenio de 1975 a 1985 como el de la bonaza cocalera de la región (Torres y Joaqui, 1995).

Para los años noventa no solo se encontraban cultivos de coca, también había una fuerte presencia de amapola. De acuerdo con el informe Panorama actual del Macizo Colombiano, realizado en 2001 por el Observatorio de Derechos Humanos (OPDHDIH), en el año 2000 había 1 500 hectáreas de amapola sembradas en el Macizo colombiano, de las cuales 312 estaban ubicadas en el departamento del Cauca. Esto influyó en el descenso de los precios de la coca, así como en los cambios en los mercados internacionales de la amapola. En este caso, los municipios de la región que más concentraron este tipo de producción fueron Almaguer, Bolívar, La Sierra, La Vega y Rosas.

Es imprescindible recordar que el área destinada a usos agrícolas del Macizo caucano es muy poca; para hacer este señalamiento se tienen como referente las áreas correspondientes a paramos, reservas forestales y naturales así como a los títulos mineros ${ }^{12}$. Es preciso anotar que las fuentes utilizadas para calcular estas distribuciones del espacio son de distintas instituciones, y se lograron mediante diferentes metodologías que tenían como eje calcular la participación de los cultivos transitorios y permanentes con respecto al total del área de la región ${ }^{13}$. Si partimos de allí, es posible encontrar que dicha área no llega a acumular más del $10 \%$, lo que permite preguntarse si un valor tan bajo tiene que ver con la presencia de cultivos de uso ilícito y la complejidad que implica el conteo sistemático de los $\operatorname{mismos}^{14}$. Por otra parte, si este tipo de

Ver Tabla 2.

Ver Tabla 3.

Se propone lo anterior teniendo en cuenta que no ha sido posible encontrar información sobre áreas cultivadas de coca y amapola para los municipios que comprende este estudio. 
cálculo se realiza con respecto al área restante, una vez se extraen las áreas correspondientes a las zonas de protección ambiental y a los títulos mineros adjudicados, se encuentra que hay una explotación tanto de los suelos destinados al uso agrícola, como de aquellos que no suponen este tipo de usos. Lo anterior implica una sobreexplotación o usos diferenciados de los mismos ${ }^{15}$.

Es pertinente retomar el caso que registra el Pupsoc en el municipio de Sotará, donde hay plantaciones de pino de la empresa Smurffit Cartón de Colombia, y las cuales han afectado los humedales. Además de contar con poca tierra, una parte de esta es destinada a un monocultivo que no aporta a la soberanía alimentaria de la localidad y a su vez afecta el medio ambiente (IEI, 2015). Las anteriores condiciones atraviesan igualmente los conflictos que se dan en la región por la propiedad y uso de la tierra, pues implica de nuevo el tema de la escasez de la misma, así como las precarias posibilidades para desarrollar economías y procesos productivos exitosos por fuera de la ilegalidad.

Tabla 3. Información sobre áreas cultivadas o para uso agrícola

\begin{tabular}{|l|c|c|c|c|}
\hline \multicolumn{1}{|c|}{ Municipio } & $\begin{array}{c}\text { Área (ha) en } \\
\mathbf{2 0 1 2}\end{array}$ & $\begin{array}{c}\text { \% respecto } \\
\text { al total 1 }\end{array}$ & $\begin{array}{c}\text { \% respecto } \\
\text { al total 2 }\end{array}$ & Fuente \\
\hline $\begin{array}{l}\text { Cultivos permanentes } \\
\text { promedio }\end{array}$ & 13686 & $8.4 \%$ & $183.6 \%$ & EVA (2012) \\
\hline $\begin{array}{l}\text { Cultivos transitorios } \\
\text { promedio }\end{array}$ & 1210 & $0.7 \%$ & $16.2 \%$ & EVA (2012) \\
\hline Total cultivos & 14896 & $9.2 \%$ & $199.8 \%$ & \\
\hline Territorios agrícolas & 154624.8419 & $95.4 \%$ & $2074.5 \%$ & IGAC (2012) \\
\hline $\begin{array}{l}\text { Región Macizo caucano } \\
\text { (total 1) }\end{array}$ & 162100.92 & & IGAC (2012) \\
\hline $\begin{array}{l}\text { Total (áreas no } \\
\text { cultivables)* }\end{array}$ & 154647.2189 & & & \\
\hline $\begin{array}{l}\text { Total 2 (total 1 - total } \\
\text { (áreas no cultivables) }\end{array}$ & 7453.701072 & & & \\
\hline
\end{tabular}

Fuente: elaboración IEI, distintas fuentes

15 En este sentido, debe tenerse en cuenta que en la región podrían encontrarse cultivos mixtos, donde no solo hay presencia de los productos agrícolas ya 


\section{Economía minera}

De acuerdo con la información que reportó en 2014 la Agencia Nacional de Minería, 34 278,79 hectáreas del Macizo caucano corresponden a títulos mineros, lo que corresponde al $21,15 \%$ del territorio; y si a esto se suma el área acumulada por las solicitudes ( 37276,59 ha), se llega a un $44,14 \%{ }^{16}$. Lo anterior corresponde a 32 títulos y 16 solicitudes, de los cuales $13(40,6 \%)$ fueron adjudicados en el año 2009, y $6(18,8 \%)$ en el 2007; mientras que la totalidad de las solicitudes fueron radicadas en el año $2014^{17}$. En este sentido, se debe tener en cuenta la expedición de la Ley 685 del 2001, mediante la cual se modifica el Código Minero para reglamentar la exploración y explotación. Con dicha expedición se redujeron las competencias del Ministerio de Ambiente y de las Corporaciones Autónomas Regionales para el otorgamiento de licencias ambientales en el sector minero, con lo cual, como señala Gómez (2013), se afecta la regulación de la actividad. Adicionalmente, se direccionó al país hacia una economía fundamentada en la extracción de minerales. Un mecanismo que reforzó esta dinámica económica fue el artículo 332 de la Constitución Política, ya que este indica que el Estado es propietario del subsuelo y los recursos naturales no renovables, lo que abre un camino legal para expropiación y, por lo tanto, para la afectación de la propiedad sobre la tierra de comunidades y privados.

mencionados. También se pueden hallar cultivos de coca y amapola, siendo los primeros para el autoabastecimiento y los segundos para la comercialización.

* Es el resultado de la resta del total de área correspondiente al Macizo caucano y las áreas de páramos, reservas forestales y naturales, y de los títulos mineros adjudicados.

16 Ver Tabla 4.

17 Ver anexos 2 y 3. 
Tabla 4. Situación minera en el Macizo caucano

\begin{tabular}{|l|c|c|}
\hline \multicolumn{1}{|c|}{ Condición } & Área (ha) & Área \% \\
\hline Títulos Mineros & 34278.79 & $21.15 \%$ \\
\hline $\begin{array}{l}\text { Solicitudes de títulos } \\
\text { mineros }\end{array}$ & 37276.59 & $23.00 \%$ \\
\hline Tierra para minería & 71555.38 & $44.14 \%$ \\
\hline Región Macizo caucano & 162100.92 & $100.00 \%$ \\
\hline
\end{tabular}

Fuente: Elaboración IEI a partir de información de la Agencia Nacional de Minería, ANM (2014)

Al respecto, el Pupsoc registra conflictos a lo largo del río Esmita, en donde desde el año 2007 la empresa Anglo Gold Ashanti ha instalado retroexcavadoras, alquilado tierras y ha funcionado mediante concesiones a particulares, además de utilizar mercurio para la extracción de oro y explotar material de arrastre (IEI, 2015). La misma situación ha sido registrada por la ANUC, quienes a su vez han alertado sobre las pretensiones de exploración y explotación minera de esta empresa en el municipio de La Sierra, así como la apropiación de los recursos hídricos por parte de la organización Ardila Lulle (IEI, 2015).

En este sentido, es importante mencionar que los titulares de las solicitudes y títulos mineros, en su mayoría son empresas privadas, como la Anglo American Colombia Exploration S.A., la Continental Gold LTDA y Carbones de los Andes S.A.. Con esto es posible anotar que el $75 \%$ de los títulos mineros han sido expedidos a empresas privadas, así como el 56,3\% de las solicitudes. Por otra parte, el 97,4\% del área que acumula los títulos mineros está en manos de empresas privadas, así como el $49,1 \%$ del área de las solicitudes ${ }^{18}$. Finalmente, la gran mayoría de los títulos y solicitudes son adjudicados para la explotación de oro y de otros minerales, de manera que el $99 \%$ de los títulos se dirigen a este recurso, así como el $77,6 \%$ de las solicitudes ${ }^{19}$.

$18 \quad$ Ver Tabla 5.

19 Ver Anexo 4. 


\section{Tabla 5. Distribución del área y número de títulos y solicitudes mineras según tipo de titular para 2014 en la región del Macizo caucano}

\begin{tabular}{|l|c|c|c|c|}
\hline \multirow{2}{*}{ Titulares } & \multicolumn{2}{c|}{ Títulos } & \multicolumn{2}{c|}{ Solicitudes } \\
\cline { 2 - 5 } & Área (ha) & $\%$ & Área (ha) & $\%$ \\
\hline Individuos & 879.07073 & $2.6 \%$ & 10372.1207 & $27.8 \%$ \\
\hline Empresas Privadas & 33399.7178 & $97.4 \%$ & 18303.7662 & $49.1 \%$ \\
\hline $\begin{array}{l}\text { Mixtos (Individuos } \\
\text { y Empresas } \\
\text { Privadas) }\end{array}$ & 0 & $0.0 \%$ & 8600.70235 & $23.1 \%$ \\
\hline Total & 34278.7886 & $100.0 \%$ & 37276.5893 & $100.0 \%$ \\
\hline \multirow{2}{*}{ Titulares } & \multicolumn{2}{|c|}{ Títulos } & & Solicitudes \\
\cline { 2 - 6 } & Número & $\%$ & Número & $\%$ \\
\hline Individuos & 8 & $25.0 \%$ & 5 & $31.3 \%$ \\
\hline Empresas Privadas & 24 & $75.0 \%$ & 9 & $56.3 \%$ \\
\hline $\begin{array}{l}\text { Mixtos (Individuos } \\
\text { y Empresas } \\
\text { Privadas) }\end{array}$ & 0 & $0.0 \%$ & 2 & $12.5 \%$ \\
\hline Total & 32 & $100.0 \%$ & 16 & $100.0 \%$ \\
\hline
\end{tabular}

Fuente: Elaboración IEI a partir de información de la Agencia Nacional de Minería, ANM (2014)

Distintos estudios y reportes dan cuenta del uso de maquinaria pesada y de químicos tóxicos -como el cianuro y el mercurio- en explotaciones mineras de la región, específicamente en Rosas, La Vega y La Sierra. Asimismo, evidencian la relación entre una economía minera y la llegada de la Fuerza Pública con el fin de garantizar el interés del capital extranjero en la exploración y explotación. Algo similar sucede con la presencia de paramilitares y/o bandas delincuenciales con el propósito de garantizar la seguridad en las minas, así como el desarrollo continuo de las distintas actividades que la práctica minera implica ${ }^{20}$.

20 Al respecto ver La Red por la Vida y los Derechos Humanos del Cauca (2011); Gómez, 2013; Mamián et al (2013); Cinep (2012) y Tocancipá (s.f.). 
Debe anotarse que, la llegada de la minería tecnificada ha significado el mejoramiento en vías de comunicación e infraestructura -como la pavimentación de los tramos entre Rosas y San Miguel-, así como la constitución de negocios locales con insumos para la minería -como ferreterías-, y la aparición de puestos para la venta de oro -en el trayecto entre Popayán y La Vega-. No obstante la minería a gran escala ha sido devastadora en términos de conservación medioambiental, y en lo que se refiere a las condiciones laborales de los habitantes. De acuerdo con la investigación de Gómez (2013), una vez terminan las tareas de dragado se acaba también la oportunidad laboral y la recuperación del ecosistema, pues al cerrar las minas o pasar a otras vetas no se logra retornar al estado inicial del territorio afectado.

Por lo tanto, lo que era una actividad minera de carácter histórico en el territorio del Macizo caucano, de tipo artesanal y con poco peso en la producción y economía de la región (Maya, 1924), tiene ahora un papel fundamental para el modelo de desarrollo implementado en los últimos cuatro gobiernos presidenciales. En particular en la consolidación de un país para la explotación de minerales, en vínculo con capitales y empresas extranjeras. Este proceso ha mezclado elementos de carácter legal e ilegal que afectan negativamente las condiciones de vida de los pobladores y el medio ambiente. Pero, en términos de la estructura de la propiedad de la tierra, es posible que existan procesos de acumulación de la misma. Es decir que para este tipo de actividad importa más el uso de la tierra y la capacidad de gestión que el Estado garantiza para acceder a esta, que la titularidad de la propiedad.

Sin embargo, como ya se ha evidenciado, hay, por un lado, terrenos distribuidos en pocos propietarios y, por el otro, una posible sobreexplotación de los recursos. Sobreexplotación que se da en medio de actividades mineras, cultivos ilícitos y sistemas productivos con un corto alcance. Todo lo anterior se da en un territorio con enormes potencialidades ambientales y geográficas como lo es el Macizo caucano, pero que, como se sostendrá a continuación, es un territorio que se ha visto 
permeado por modelos de desarrollo que fomentan condiciones de despojo más que de redistribución y reconocimiento para sus pobladores.

\section{La dimensión social: presencias del Estado y organización Social}

\section{Presencia débil del Estado}

Existen diversos indicadores y datos agregados que ayudan a caracterizar las condiciones de vida de una población. No obstante, para este caso, es preciso mencionar que en el país la disponibilidad de ciertos indicadores a nivel municipal es bastante escasa, lo que limita la información, y, por tanto, la posibilidad de análisis. Sin embargo, es posible iniciar con las obras civiles que cruzan el territorio, pues estas afectan no solo la dinámica económica de la región, también dan cuenta de la presencia del Estado en el territorio. En este sentido, la red vial del Macizo caucano es bastante escasa. A pesar de que tres de los municipios de la región son atravesados por la vía Panamericana (Sotará, Rosas y La Sierra), la conectividad entre los cinco municipios se da principalmente mediante vías sin pavimentar y las transitables en tiempo seco. Además, en algunos casos, para movilizarse de un municipio a otro debe llegarse primero a la vía Panamericana y luego tomar las carreteras que llevan a los centros poblados o cabeceras municipales, como es el caso de los trayectos entre Sotará y los demás municipios. 


\section{Mapa 1. Red vial del Macizo caucano}

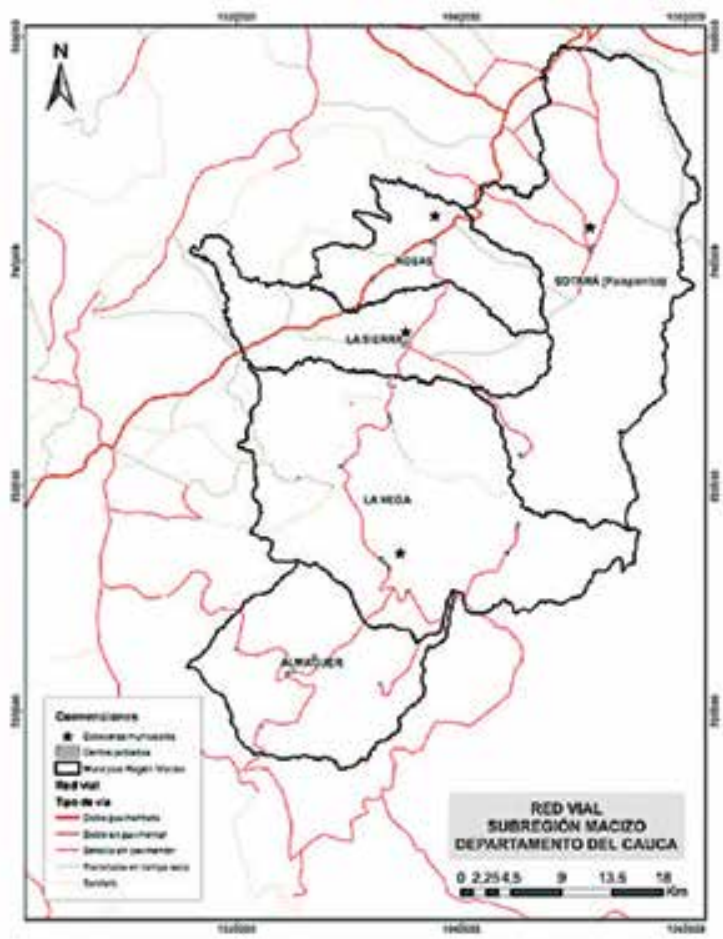

Fuente: Elaboración IEI a partir de información del Instituto Geográfico Agustín Codazzi, IGAC (2014)

El indicador de Necesidades Básicas Insatisfechas de la población, NBI, presentó cifras preocupantes, pues son superiores a las nacionales y departamentales. De acuerdo con los datos ofrecidos en la investigación de Herrera (2003), para el año 1993 la región tenía una población con NBI levemente superior (69,2\%), aunque a nivel municipal no se identificó la misma característica. En este sentido, entre un censo y otro, la población con NBI aumentó en los casos de Almaguer, pasando de 86,8\% en 1993 a 88,5\% en el 2005 y en Rosas, donde se pasó de 62,6\% a $65,9 \%$, respectivamente. Los demás municipios redujeron dicha cifra, pero en no más de 5 puntos porcentuales aproximadamente, de manera 
que en la mayoría de los casos la población con NBI supera el 50\%. La situación en términos de la distribución de la población en cabecera/ resto es más desalentadora, pues las condiciones de las personas que viven en las zonas rurales son mucho más agudas que las de quienes viven en las cabeceras. Particularmente es preocupante el caso de Almaguer, donde el $92,1 \%$ de la población rural vive con NBI.

\section{Tabla 6. Población con Necesidades Básicas Insatisfechas. Censos de 1993 y 2005.}

\begin{tabular}{|l|c|c|c|c|}
\hline \multirow{2}{*}{ Zona } & \multicolumn{2}{|c|}{ NBI en \% (2005) } & \multicolumn{2}{c|}{ NBI en \% (1993)* } \\
\cline { 2 - 5 } & Cabecera & Resto & Total & Total \\
\hline Total nacional & 19.7 & 53.5 & 27.8 & - \\
\hline Cauca & 24.3 & 62.0 & 46.6 & - \\
\hline Macizo & 36.2 & 71.0 & 67.9 & $69.2^{* *}$ \\
\hline Almaguer & 50.8 & 92.1 & 88.5 & 86.8 \\
\hline La Sierra & 41.8 & 59.2 & 56.9 & 61.0 \\
\hline La Vega & 30.8 & 74.0 & 70.6 & 73.8 \\
\hline Rosas & 26.5 & 71.6 & 65.9 & 62.6 \\
\hline Sotará & 30.9 & 57.9 & 57.3 & 62.0 \\
\hline
\end{tabular}

Fuente: Elaboración IEI a partir de datos suministrados por el Departamento Nacional de Estadística DANE, consultados el 27 de septiembre de 2015

Otro factor que resulta preocupante es la cobertura de los servicios públicos. De acuerdo al Censo de 2005, es posible identificar que nuevamente la región del Macizo caucano tiene peores condiciones a las del departamento y que esta situación se profundiza al diferenciar la información en términos de cabecera/resto. El Cauca tiene una cobertura de $93,0 \%$ en las viviendas de las cabeceras, mientras que en la zona

* Los datos correspondientes a 1993 fueron tomados de la investigación de Herrera (2003); no se cuenta con información desagregada para cabecera y resto.

** Cálculo propio mediante promedio. 
rural es del $42,6 \%$, es decir que a nivel regional las cifras son de $91,5 \%$ y $37,9 \%$, respectivamente ${ }^{21}$.

\section{Presencia fuerte del Estado}

El monopolio del uso de la fuerza es otra de las características que se puede analizar, ya que es clave en la teoría social para estudiar y definir a los estados nacionales. En el caso del Macizo caucano parece que el uso de la fuerza ha sido una de las vías privilegiada por los últimos gobiernos, en términos de presencia y acción del Estado colombiano. Para comprender esto, es necesario anotar que este territorio hace parte de la jurisdicción que le corresponde a la Tercera División del Ejército -con puesto de mando en la ciudad de Popayán-. Dicha división cubre un área de 86470 kilómetros cuadrados, y según datos de 2015 del Ejército Nacional, estos están distribuidos entre los departamentos de Valle, Valle del Cauca y Nariño. En 2003 se creó el Batallón de Alta Montaña No. 4 Gr. Benjamín Herrera Cortes, ubicado en el Páramo de las Papas, corregimiento de Valencia, municipio de San Sebastián (Cauca). Este batallón cubre el territorio del Macizo colombiano con el propósito de controlar la presencia y tránsito de los distintos actores armados ilegales presentes en la región. No obstante, este tipo de presencia del Estado no ha logrado el control total del uso de la fuerza y la violencia, pues tanto la guerrilla de las FARC-EP como la del ELN tienen una presencia histórica en la zona, en particular a partir de los años ochenta del siglo XX (Medina, 2011). A esta situación se suma la llegada de paramilitares de las AUC a finales de la década de los noventa y la consolidación de bandas delincuenciales. Adicionalmente, debe anotarse que la presencia de batallones y brigadas móviles no son garantía de seguridad y respeto de los derechos de los pobladores. Según la Red de Derechos Humanos del Sur Occidente Colombia (2011), en la zona del Macizo caucano se han denunciado vínculos entre Policía y/o Ejercito con paramilitares y guerrillas para el tráfico de drogas; así como la la intimidación de

$21 \quad$ Ver Anexo 5. 
líderes sociales, el acoso a la población -abusos sexuales, control de la locomoción-, y el privilegio al cuidado y aseguramiento de instalaciones de empresas privadas -generalmente mineras y de agroindustria-.

\section{Organización y movilización social}

La presencia débil del Estado no es una situación identificada solo en los últimos años, y el Movimiento del Macizo Colombiano es evidencia de ello; pues existen denuncias de la población en torno a este tema desde mediados del siglo $\mathrm{XX}^{22}$. En este sentido, las demandas por inversión social en vías de comunicación y acceso, servicios públicos, educación, salud y proyectos agropecuarios, reunían en un solo movimiento a diversos actores sociales: maestros de escuelas, jornaleros, estudiantes, campesinos e indígenas (Tocancipá, s.f.). No obstante, es en las décadas de los ochenta y noventa donde las protestas, concretadas en distintas tomas de la vía Panamericana, consiguen una repercusión regional y nacional. Por medio de estas movilizaciones no solo se posicionaron reclamos respecto a las precarias condiciones de los apartados municipios, también se inició el forjamiento de procesos identitarios y colectivos en torno a las nociones de campesinado y región Macizo (Aldana, 1998).

Desde 1985 y hasta el año 2000 se registraron siete bloqueos, y de estos el de mayor duración e impacto fue el de noviembre de 1999 (Tocancipá, s.f.). Esta movilización se generó debido a los incumplimientos por parte del Estado frente a los acuerdos logrados en la movilización de 1996. Para el levantamiento de 1999, Zambrano (2001) reporta 30.000 personas taponando durante 25 días la vía Panamericana en la frontera entre los departamentos de Cauca y Nariño. Además, el mismo autor indica que varias veces la población fue señalada, por parte del Gobierno Nacional, de ser militante de la guerrilla, y fue violentada mediante el uso de la fuerza pública con lo que se intentó fragmentar la movilización.

22 Al respecto ver Aldana (1998); Zambrano (2001) y Tocancipá (s.f.). 
Para los manifestantes la vía Panamericana fue un lugar estratégico, pues al ser una ruta que comunica sur y norte del país, así como con otros países de la región, se constituye como bien público susceptible a ser medio de acción para elevar demandas (Tocancipá, s.f.).

Un proyecto vial como la vía Panamericana, que suponía progreso y desarrollo, pues canalizaba el transporte no solo de personas sino también de bienes y mercancías, no había generado el supuesto impacto económico en las poblaciones aledañas. Aun así, esta vía se convirtió en medio de visibilización y presión. De acuerdo con Tocancipá (s.f.), este tipo de acción colectiva da cuenta, una vez más, del debilitamiento de los partidos políticos tradicionales para la mediación y representación de la sociedad frente al Estado; por lo tanto, también de nuevas formas de hacer política. En este sentido, Aldana (1998) menciona que entre los años de 1995 y 1997 los movimientos cívicos de la región lograron tener quince alcaldías y, bajo la categoría de “otros”, la Registraduría reconoció diez escaños más. En esta clasificación entraron coaliciones, alianzas y organizaciones comunitarias ${ }^{23}$.

\section{Conflicto armado}

Las dinámicas del conflicto armado en el suroccidente Colombiano han sido de largo aliento y con distintas características, lo cual depende, como dice Echandía (2004) de la época y contextos en los que se estudie - Abocarse a la comprensión del mismo implica lograr un análisis interdisciplinar, el cual permita vincular aspectos históricos, económicos, sociales y culturales; pero para esto hay que tener en cuenta una perspectiva escalar donde importen elementos de carácter nacional, regional

23 Es importante mencionar que actualmente las organizaciones del Macizo caucano que componen el CIMA son los Procesos de Vida Digna Campesina en La Sierra y en Rosas. También se encuentran ejercicios organizativos vinculados al Pupsoc, como es el Proceso Campesino y Popular de La Vega, las Zonas de Reserva Campesina del Macizo y la Coordinación Campesina de Sotará. Además hay presencia de la ANUC en Almaguer, La Vega y Sotará (IEI, 2015). 
y local. Aunque esta es una tarea que excede los objetivos del presente estudio, dar cuenta de la estructura de la propiedad de la tierra rural en la región, es un ejercicio que ineludiblemente debe vincular las características geográficas, demográficas e históricas. Del mismo modo es fundamental no perder de vista los hitos económicos y sociales trabajados hasta el momento en relación con los actores armados presentes en el territorio y sus intereses. La importancia de las anteriores observaciones radica en que la problemática mencionada hasta ahora se da en términos de las disputas por la tierra, su propiedad y uso, y en la manera en como sobre esta influye el conflicto armado, en tanto se ha intentado resolver mediante la vía armada por algunos grupos sociales ${ }^{24}$.

\section{Los actores armados e intereses}

Para el caso del Macizo caucano es posible identificar cuatro actores armados principales: la guerrilla de las FARC-EP y el ELN, los paramilitares, otros actores armados ilegales, como las Bacrim, y la fuerza pública. Las FARC-EP tienen presencia desde 1980, mediante los frentes 8 y 60, y el ELN desde la misma década a través de las Compañías Manuel Vásquez Castaño y Milton Hernández, y de la Columna Móvil Camilo Cien Fuegos (Medina, 2011 y Medina, s.f.). Por su parte, el paramilitarismo incursionó en el territorio desde finales de la década de los noventa, y lo hizo mediante los Bloques Calima, Farallones y Sur Independiente (MOE, 2010). En cuanto a otros actores armados ilegales, es posible dar cuenta de bandas delincuenciales que muchas veces operan en conjunto con las guerrillas y/o los paramilitares. Finalmente -como ya se mencionó en el acápite anterior-, en la región hay presencia de la Policía y el Ejército Nacional, mediante estaciones ubicadas en las cabeceras de los municipios; una muestra de ello es el Batallón de Alta Montaña instalado en el año 2003 y la Brigada Móvil N²9 en el 2005 (MOE, 2010).

24 Al respecto ver CINEP (2012); Medina (2011) y Medina (s.f.). 
Los argumentos para constituirse, las formas de incursión en los municipios, los repertorios de acción y los propósitos políticos de cada actor armado, aunque diferentes, tienen puntos de encuentro en los motivos estratégicos que generan interés en el territorio. Así, la región del Macizo caucano es relevante en dos sentidos: uno, como corredor para la movilidad, pues permite conectarse con salidas hacia el océano pacífico, con la vía Panamericana y con departamentos del nororiente; y, dos, como fuente de ingresos y acumulación a partir de los usos del suelo y de sus recursos naturales, en particular para el cultivo y procesamiento de la hoja de coca y la amapola, para la minería y para la explotación de agua mineral.

La primera condición ha sido explotada históricamente por los grupos guerrilleros, en tanto permite la conectividad con distintas zonas del país, así como el repliegue en momentos de enfrentamientos con la fuerza pública. No obstante, la actuación guerrillera también tiene un fuerte vínculo con la presencia diferenciada del Estado. Al ser una región poco atendida en materia de servicios públicos y fuertemente segmentada en términos de clases sociales y grupos étnicos, como señala Medina (2011), se presenta como escenario fértil para la consolidación política y social de las propuestas y consignas guerrilleras, en especial durante de los años ochenta y parte de los noventa del siglo XX. En este sentido, las acusaciones de vínculo entre los movimientos sociales y los grupos guerrilleros ha afectado la permanencia y desarrollo de los movimientos, en tanto se convierten en objetivo militar de la fuerza pública y de otros actores armados ilegales, como los paramilitares. Este tipo de acusaciones desconocen formas de movilización y protesta social distintas a la vía armada, que, en el caso del Macizo caucano, han sido importantes y de larga data. Por otra parte, el uso de los cultivos ilícitos para la financiación de la estructura guerrillera es una relación innegable que ha afectado a los pobladores, las economías y el medio ambiente. En este sentido, tanto las FARC-EP como el ELN controlan y protegen zonas de cultivo, laboratorios para el procesamiento y rutas de salida de la mercancía.

En cuanto a la presencia del paramilitarismo y otros grupos armados ilegales, el uso de los suelos y los recursos naturales tiene que ver tanto 
con actividades económicas legales como ilegales, la minería, el monocultivo de pino y la extracción de agua son las principales. En este contexto, la condición del Macizo como corredor estratégico resulta ser relevante en tanto permite garantizar la movilidad y requiere del control territorial para distintos propósitos: 1. la salida y comercialización de la mercancía producto del procesamiento de cultivos ilícitos; 2 . la llegada y permanencia de empresas privadas nacionales y multinacionales de naturaleza extractiva, enfocadas en la explotación de oro, pino y agua; 3. la convivencia paralela con actividades mineras ilegales, en tanto los títulos no han sido solicitados ni adjudicados; y 4. el sostenimiento de una estructura política cimentada en el predominio de los partidos políticos tradicionales o de nuevos partidos que tienen vínculos con intereses privados.

Por su parte, la presencia fuerte de la Fuerza Pública se da a partir de la primera década del siglo XXI, lo que ha sido relacionado con la implementación de la política de Seguridad Democrática de los periodos presidenciales de Álvaro Uribe Vélez. Esta implementación se caracterizó por el incremento del pie de fuerza de la Policía y el Ejército y por la persecución frontal de las guerrillas (CINEP, 2012). Este tipo de presencia perdura en los periodos presidenciales de Juan Manuel Santos, de la mano con la implementación y consolidación de Planes Nacionales de Desarrollo, PND, que privilegian la economía extractiva frente a la agrícola y de servicios. Por lo tanto, la Fuerza Pública garantiza la seguridad en tanto movilidad y permanencia de los ciertos actores sociales, en detrimento de una seguridad ambiental y alimentaria. Entonces, aunque este no es el único tipo de presencia estatal en la región, ya que institucionalmente operan otras dependencias, en términos del conflicto armado podría afirmarse que la vía militarista ha sido privilegiada.

\section{Los impactos del conflicto armado}

Corpoafro ha identificado en los municipios de Rosas, La Sierra, norte del Patía y sur del Tambo, además en la franja del río San Jorge y Guachicono, la presencia de actores armados ilegales que llevan a cabo explotación minera, por lo cual intimidan a los pobladores de la zona 
(IEI, 2015). Por su parte, la ANUC ha dado cuenta de minería ilegal en manos de las FARC y el ELN, así como la presencia de cultivos de uso ilícito en La Vega. En este contexto, el desplazamiento es una de las situaciones que más viven las personas que hacen parte de los registros de la Unidad para la Atención y Reparación Integral a las Víctimas. Un $53,7 \%$ (2994 casos) de los hechos ocurridos entre 1984 y 2015 en el Macizo caucano son desplazamiento, luego está el homicidio con un $22,3 \%$, las amenazas con un $13,1 \%$ y, finalmente, otros hechos como actos terroristas, delitos sexuales, desaparición forzada, minas antipersonal, pérdida de muebles o inmuebles, secuestro, tortura y vinculación de niños y adolescentes, acumulan el $10,5 \%$ en todo el periodo.

Gráfico 2. Participación porcentual de la ocurrencia de situaciones que victimizan a las personas en el Macizo caucano (1984-2015)

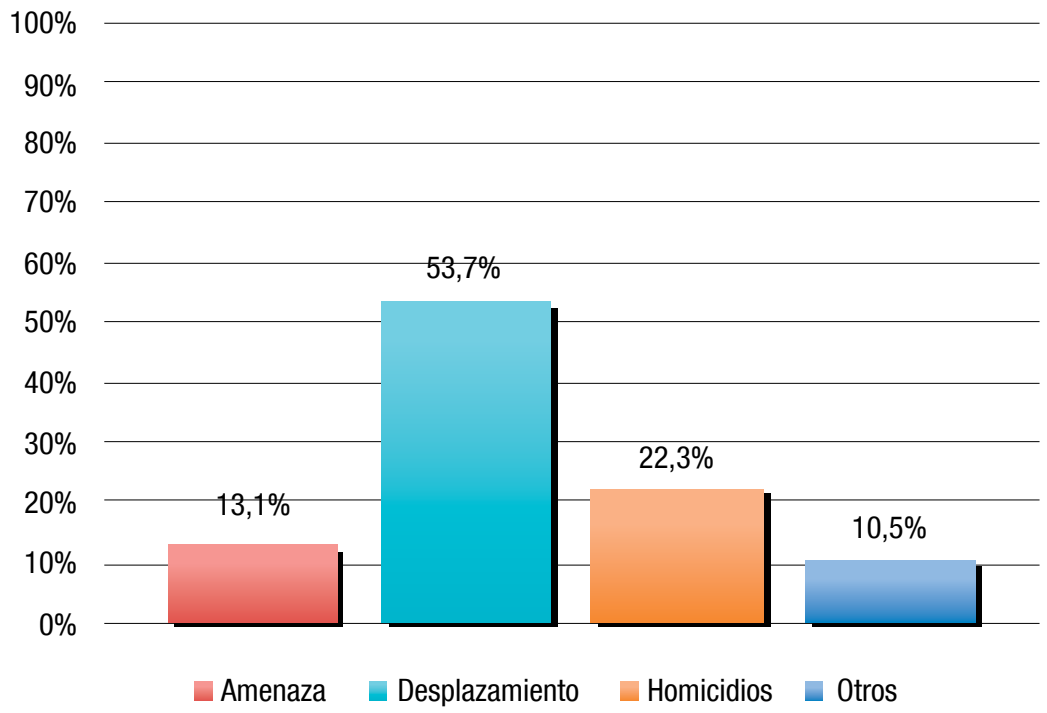

Fuente: Elaboración del IEI a partir de la información proporcionada por la Unidad para la Atención y Reparación Integral a las Víctimas. Consulta en línea: 4 de octubre de 2015 (http://cifras.unidadvictimas.gov.co/)

Aunque la fuente de información utilizada para la gráfica anterior no da cuenta del actor que desencadena la situación que afecta a la víctima, 
al observar la tendencia de los cuatro hechos que allí se relacionan, es posible proponer que el desplazamiento es un fenómeno que se da durante todo el periodo comprendido entre 1984 y 2015; También se puede proponer que el fuerte aumento a partir de 1999 presenta relación con la llegada de los grupos paramilitares a la zona. De hecho, en el año 2001 se llega a un pico de 152 casos y luego la tendencia continúa en aumento, con años puntuales de descenso (2003, 2010 y 2015) sin llegar a retornar a alguna de las cifras previas a 1999. En cuanto a los homicidios, es posible observar que la tendencia es más o menos estable a lo largo del periodo, oscilando entre los 46 y 23 casos anualmente. De acuerdo con este tipo de información es posible proponer que los procesos de consolidación del modelo de desarrollo económico ya descrito (extractivista y de despojo) van de la mano con la presencia de actores armados legales e ilegales. Esto se debe a que dichas presencias garantizan la permanencia de las actividades económicas privilegiadas en el territorio, así como la afectación y exterminio de procesos sociales populares que cuestionen a los mismos.

\section{Gráfico 3. Ocurrencia de los principales delitos entre 1984 y 2015 en el Macizo caucano}

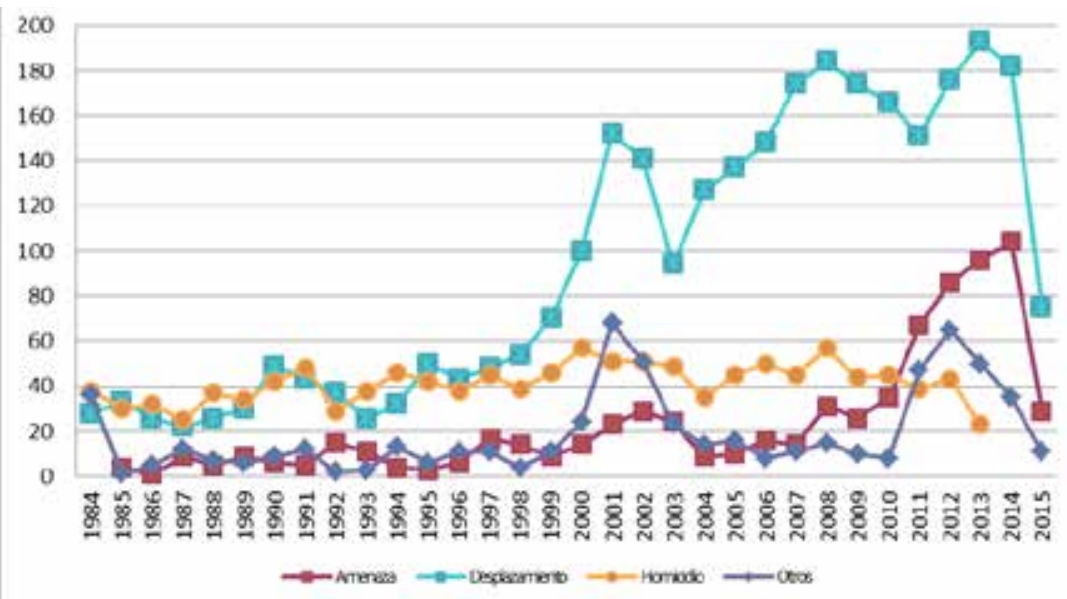

Fuente: Elaboración del IEI a partir de la información proporcionada por La Unidad para la Atención y Reparación Integral a las Víctimas. Consulta en línea: 4 de octubre de 2015 (http://cifras.unidadvictimas.gov.co/) 


\section{Reflexiones finales}

En la región del Macizo caucano se encuentran múltiples actores sociales y políticos, recursos ambientales y económicos, niveles diferenciados de institucionalidad estatal y formas de economía que transitan entre la legalidad precarizada y una ilegalidad enriquecida que en distintos nivelas impacta la calidad de vida de sus habitantes. La presencia del Estado ha privilegiado el uso de la fuerza y la búsqueda de control del territorio, pero no para brindar seguridad a los habitantes de esta región sino para garantizar la entrada y permanencia de capitales extranjeros y privados. La razón de ser de esto se encuentra en los intereses políticos por una economía extractiva minera y ajena a las necesidades y reclamaciones de las organizaciones sociales presentes en el territorio. Los procesos de despojo y acumulación pueden verse igualmente reflejados en las condiciones de las víctimas del conflicto armado, así como en las disputas por los usos de la tierra. Esto hace que la agricultura y lo agropecuario queden relegados a un plano de subsistencia o comercio local y regional con una dinámica débil y en pobres condiciones técnicas.

Pero dichas disputas -que también implican la propiedad de la tierrano se dan únicamente con el Estado, la empresa privada y los actores armados ilegales. Los conflictos entre las distintas organizaciones sociales presentes en el territorio evidencian nuevamente la pluralidad de actores sociales que constituyen al Macizo caucano. Aquí la dimensión de lo étnico juega un papel fundamental, pues ofrece a las comunidades organizadas (como la indígena y la afro) mecanismos legales que impactan la estructura de la propiedad de la tierra mediante figuras especiales de ordenamiento territorial. Adicionalmente, estos conflictos se dan en medio de una escasez de tierras disponibles para ejercer formas de economía alternativas, que privilegien la agricultura, la economía campesina y la familiar. Dicha escasez se encuentra no solo vinculada al modelo económico sino también a las figuras de ordenamiento ambiental de la región.

Por lo tanto, abordar un tema como el de la interculturalidad, la convivencia y las gobernanzas territoriales, debe considerar en sus recursos 
explicativos y argumentativos las condiciones materiales así como los contextos históricos, políticos y económicos. En estos contextos emergen tanto los encuentros como los conflictos y desencuentros de quienes habitan territorios determinados. En el caso del Macizo caucano, los derechos territoriales de las poblaciones rurales y étnicas han resultado ser un mecanismo de doble filo. Con esto se hace referencia a que, por un lado, fragmentan espacios de convivencia social y productiva, pero, por el otro, fortalecen procesos de resistencia en una clave específica: la cultural entendida como étnica. En este contexto gana terreno la implementación de políticas macroeconómicas, mediante la concesión de títulos mineros o la presencia de la fuerza pública, así como también mediante procesos consolidación de economías extractivas e ilegales que logran afectar el territorio en niveles locales. Entre las afectaciones más relevantes están la contaminación de un río, la expansión de un tipo de cultivo, la focalización de recursos para el sustento de dicha economía más no para el mejoramiento de la calidad de vida de los pobladores, entre otros temas, que implica impactos a nivel regional y nacional.

Finalmente, es preciso mencionar que el presente artículo carece de una dimensión que recupere, de forma cualitativa y profunda, las construcciones de sentido sobre el territorio, y que introduzca en el análisis las subjetividades políticas emergentes en los territorios. Es preciso avanzar en este tipo de investigación y generar vínculos con las aproximaciones ofrecidas en este artículo. De este modo será posible tejer explicaciones más agudas que tengan en cuenta condiciones estructurales de la realidad social, así como las posibilidades y capacidad de agencia de los actores sociales que dan sentido y vivencian el Macizo caucano.

\section{Bibliografía}

Alto Comisionado de las Naciones Unidas para los Refugiados (2004). Algunos Indicadores sobre la Situación de los Derechos Humanos en la Región del Macizo caucano. Recuperado de: http://www.acnur.org/t3/uploads/media/667. pdf?view $=1$. 
Aldana, W. (1998). "Una expedición por el Macizo y los conflictos regionales del Cauca”. En El Contexto Espacial y Demográfico. Colombia: Fescol y Universidad Nacional de Colombia. 141-153.

Bateman, A. (1961). "La Carretera Panamericana en Colombia”. En Boletín de la Sociedad Geográfica de Colombia, No. 69-70, Vol. XIX.

Cancillería de Colombia (2015). Reservas de Biósfera. Recuperado de: http:// www.cancilleria.gov.co/unesco/area/natural/reserve.

CINEP (2012). Cien días vistos por el CINEP ¿Avanzar hacia dónde? Bogotá: CINEP.

Del Cairo Silva, C. (s.f.). El Macizo Colombiano: Una Región en Permanente Construcción. Colombia. Popayán: Fundación Espacio Abierto.

Echandía, C. (2004) La Guerra por el Control Estratégico en el Suroccidente Colombiano, Sociedad y Economía, 7, 2004, pp. 65-89, Universidad del Valle, Cali, Colombia

Ejército Nacional (2015). Recuperado de: http://www.ejercito.mil.co/index. php?idcategoria $=321863$.

García, C. (2007). Enfoque sobre "región”. En Elementos para una discusión. II Seminario interno, ODECOFI. Octubre 8 y 9 de 2007. Recuperado de: http:// bibliotecadigital.icesi.edu.co/biblioteca_digital/bitstream/item/3682/2/ ENFOQUES_SOBRE_REGION.pdf

Gómez, A. (2013). "Efectos Sociales y Ambientales del proceso de exploración minera en La Vega, Cauca. 2010-2012” (tesis de pregrado). Universidad del Valle, Cali, Colombia.

Herrera, L. (2003). Región, Desarrollo y Acción Colectiva. Movimiento de Integración del Macizo Colombiano. Bogotá: CINEP.

IEI (s.f.). Des-encuentros Territoriales. Volumen I. La emergencia de los conflictos interétnicos e interculturales en el departamento del Cauca. Cali: Universidad Javeriana.

(2013). Determinación de las Unidades Agrícolas Familiares (UAF) para el departamento del Cauca. Cali: Universidad Javeriana.

(2015). Informe preliminar sobre los conflictos territoriales, los procesos organizativos rurales y la acción institucional en el departamento del Cauca. Cali: Universidad Javeriana. 
Maya, T. (1924). Geografía del Departamento del Cauca. Colombia: Imprenta Caucana.

MOE (2010) Factores de Riesgo Electoral 2010. Cauca, Colombia. Recuperado de: http://moe.org.co/home/doc/moe_mre/caucalibro.pdf.

Mamián, C. et al (2013). Prácticas de resistencia de las comunidades campesinas y organizaciones sociales en torno al agua, en contextos de La Vega y Sucre, Macizo Colombiano. Popayán: Universidad de Manizales, sede Popayán.

Medina, C. (2011). FARC-EP. Flujos y reflujos: la guerra en las regiones. Bogotá: Universidad Nacional.

Medina, C. (s.f.). E.L.N. Notas para una historia política. Bogotá: Universidad Nacional.

Nates, B. (2002). De lo bravo a lo manso. Territorio y Sociedad en los Andes Macizo Colombiano. Ecuador: Ediciones Abya-Yala.

Observatorio del Programa Presidencial de Derechos Humanos y Derecho Internacional Humanitario (2001). Panorama actual del Macizo Colombiano. Colombia. Recuperado de:

Red por la Vida y los Derechos Humanos del Cauca (2011). Informe Derechos Humanos. Recuperado de: http://www.askonline.ch/fileadmin/user_upload/ documents/Thema_Menschenrechte/Berichte_Organisationen/INFORME_2011_DDHH_CAUCA_-_RED_POR_LA_VIDA.pdf.

Tocancipá, J. (s.f.) Movimientos Sociales, cultura y poder regional. El caso del Movimiento del Macizo Colombiano (MMC), Colombia. Recuperado de: http://www.academia.edu/7979700/Movimientos_Sociales_cultura_ pol\%C3\% ADtica_y_poder_regional._El_caso_del_Movimiento_del_Macizo_Colombiano_MMC_1

Torres, M. (2001) “Cauca Geodiverso”. En Historia, Geografía y Cultura del Cauca. Territorios Posibles. Tomo I. Colombia: CRC, Lotería del Cauca y Universidad del Cauca. 109-124.

Torres, V. y Joaqui, L. (1995). Auge y crisis de la producción de coca en Bolívar Cauca, Región, No. 3-4, pp.49-65.

Zambrano, C. (2001) "Conflictos por la hegemonía regional. Un análisis del movimiento social y étnico del Macizo colombiano”. En Movimientos sociales, Estado y democracia en Colombia. Colombia: Universidad Nacional de Colombia. 260-285. 


\section{Anexos}

\section{Anexo 1. Elementos sociodemográficos según municipio y región Macizo caucano (2015)}

\begin{tabular}{|c|c|c|c|c|c|c|c|c|c|}
\hline \multirow[b]{2}{*}{ Unidad } & \multicolumn{9}{|c|}{2015} \\
\hline & Total & $\begin{array}{c}\text { Distribución } \\
\text { región }\end{array}$ & Cabecera & Resto & Hombres & Mujeres & Indígenas & $\begin{array}{c}\text { Afro- } \\
\text { colombianos }\end{array}$ & $\begin{array}{c}\text { Ninguna } \\
\text { de las } \\
\text { anteriores }\end{array}$ \\
\hline Cauca & & 1379.169 & $39.7 \%$ & $60.3 \%$ & $50.7 \%$ & $49.3 \%$ & $21.5 \%$ & $22.2 \%$ & $56.3 \%$ \\
\hline $\begin{array}{c}\text { Macizo } \\
\text { caucano }\end{array}$ & 107719 & $7.8 \%$ & $7.8 \%$ & $92.2 \%$ & $52.2 \%$ & $47.8 \%$ & $25.6 \%$ & $1.6 \%$ & $72.8 \%$ \\
\hline Almaguer & 21243 & $19.7 \%$ & $7.6 \%$ & $92.4 \%$ & $52.3 \%$ & $47.7 \%$ & $20.9 \%$ & $0.1 \%$ & $79.0 \%$ \\
\hline La Sierra & 10643 & $9.9 \%$ & $14.1 \%$ & $85.9 \%$ & $53.9 \%$ & $46.1 \%$ & $21.6 \%$ & $11.3 \%$ & $67.1 \%$ \\
\hline La Vega & 45563 & $42.3 \%$ & $7.1 \%$ & $92.9 \%$ & $51.5 \%$ & $48.5 \%$ & $27.6 \%$ & $0.1 \%$ & $72.3 \%$ \\
\hline Rosas & 13302 & $12.3 \%$ & $12.8 \%$ & $87.2 \%$ & $53.3 \%$ & $46.7 \%$ & $2.5 \%$ & $3.8 \%$ & $93.7 \%$ \\
\hline Sotará & 16968 & $15.8 \%$ & $2.1 \%$ & $97.9 \%$ & $52.1 \%$ & $47.9 \%$ & $46.7 \%$ & $0.0 \%$ & $53.3 \%$ \\
\hline
\end{tabular}

Fuente: Elaboración del IEI con datos del Departamento Nacional de Estadística DANE (ajustes y proyecciones de población 1985-2020). Fecha de consulta: 25 de agosto de 2015. La información de pertenencia étnica corresponde a una proyección elaborada por el sistema de consulta en línea TANGARA.

\section{Anexo 2. Número de títulos y solicitudes de títulos mineros en la región del Macizo caucano a 2014}

\begin{tabular}{|c|c|c|}
\hline & Número & \% \\
\hline Títulos a 2014 & 32 & $66.7 \%$ \\
\hline Solicitudes mineras a 2014 & 16 & $33.3 \%$ \\
\hline Total & 48 & $100.0 \%$ \\
\hline
\end{tabular}

Fuente: Elaboración del IEI a partir de información de la Agencia Nacional de Minería ANM (2014) 


\section{Anexo 3. Fecha de titulación de títulos mineros en la región del Macizo caucano}

\begin{tabular}{|c|c|c|}
\hline Año & Títulos & \% \\
\hline 1999 & 1 & $3.1 \%$ \\
\hline 2006 & 2 & $6.3 \%$ \\
\hline 2007 & 6 & $18.8 \%$ \\
\hline 2008 & 1 & $3.1 \%$ \\
\hline 2009 & 13 & $40.6 \%$ \\
\hline 2010 & 3 & $9.4 \%$ \\
\hline 2011 & & $0.0 \%$ \\
\hline 2012 & 3 & $9.4 \%$ \\
\hline 2013 & 2 & $6.3 \%$ \\
\hline 2014 & 1 & $3.1 \%$ \\
\hline Total & 32 & $100.0 \%$ \\
\hline
\end{tabular}

Fuente: Elaboración de IEI a partir de información de la Agencia Nacional de Minería ANM (2014)

Anexo 4. Recursos a explotar que reportan los títulos y las solicitudes mineras en la región del Macizo caucano a 2014

\begin{tabular}{|c|c|c|c|c|}
\hline \multirow{2}{*}{ Recursos } & \multicolumn{2}{|c|}{ Títulos mineros } & \multicolumn{2}{c|}{ Solicitudes de títulos mineros } \\
\cline { 2 - 5 } & Área (Ha) & $\%$ & Área (Ha) & $\%$ \\
\hline Oro & 33930.3181 & $99.0 \%$ & 28939.9245 & $77.6 \%$ \\
\hline Construcción & 348.470416 & $1.0 \%$ & 10.238332 & $0.0 \%$ \\
\hline $\begin{array}{c}\text { Otros } \\
\text { minerales }\end{array}$ & & & 8326.4265 & $22.3 \%$ \\
\hline Total & 34278.7886 & $100.0 \%$ & 37276.5893 & $100.0 \%$ \\
\hline
\end{tabular}

Fuente: Elaboración del IEI a partir de información de la Agencia Nacional de Minería ANM (2014) 
Anexo 5. Servicios Públicos (Energía, Acueducto y Alcantarillado). Participación porcentual a nivel nacional, departamental, regional y municipal

\begin{tabular}{|c|c|c|c|}
\hline \multicolumn{4}{|c|}{ Servicios Públicos } \\
\hline \multirow{2}{*}{ Zona } & \multicolumn{3}{|c|}{ Energía } \\
\hline & Cabecera & Resto & Total \\
\hline Cauca & $95.8 \%$ & $70.0 \%$ & $80.7 \%$ \\
\hline Macizo & $97.0 \%$ & $70.0 \%$ & $72.2 \%$ \\
\hline Almaguer & $96.4 \%$ & $51.0 \%$ & $54.8 \%$ \\
\hline La Sierra & $95.0 \%$ & $80.4 \%$ & $82.6 \%$ \\
\hline La Vega & $99.8 \%$ & $76.5 \%$ & $78.1 \%$ \\
\hline Rosas & $96.4 \%$ & $72.6 \%$ & $75.8 \%$ \\
\hline Sotará & $97.0 \%$ & $72.1 \%$ & $72.7 \%$ \\
\hline \multirow{2}{*}{ Zona } & \multicolumn{3}{|c|}{ Acueducto } \\
\hline & Cabecera & Resto & Total \\
\hline Cauca & $93.0 \%$ & $46.8 \%$ & $66.0 \%$ \\
\hline Macizo & $92.3 \%$ & $34.7 \%$ & $39.5 \%$ \\
\hline Almaguer & $96.7 \%$ & $15.0 \%$ & $21.8 \%$ \\
\hline La Sierra & $94.5 \%$ & $69.6 \%$ & $73.4 \%$ \\
\hline La Vega & $91.2 \%$ & $39.9 \%$ & $43.6 \%$ \\
\hline Rosas & $86.7 \%$ & $25.7 \%$ & $34.0 \%$ \\
\hline Sotará & $94.0 \%$ & $32.7 \%$ & $34.1 \%$ \\
\hline \multirow{2}{*}{ Zona } & \multicolumn{3}{|c|}{ Alcantarillado } \\
\hline & Cabecera & Resto & Total \\
\hline Cauca & $90.4 \%$ & $10.9 \%$ & $43.9 \%$ \\
\hline Macizo & $85.1 \%$ & $9.0 \%$ & $15.3 \%$ \\
\hline Almaguer & $91.2 \%$ & $6.0 \%$ & $13.1 \%$ \\
\hline La Sierra & $79.3 \%$ & $1.2 \%$ & $13.0 \%$ \\
\hline La Vega & $90.3 \%$ & $20.0 \%$ & $25.0 \%$ \\
\hline Rosas & $77.6 \%$ & $4.9 \%$ & $14.8 \%$ \\
\hline Sotará & $92.0 \%$ & $3.0 \%$ & $5.1 \%$ \\
\hline
\end{tabular}




\begin{tabular}{|c|c|c|c|}
\hline \multirow{2}{*}{ Zona } & \multicolumn{3}{|c|}{ Total } \\
\cline { 2 - 4 } & Cabecera & Resto & Total \\
\hline Cauca & $93.0 \%$ & $42.6 \%$ & $63.5 \%$ \\
\hline Macizo & $91.5 \%$ & $37.9 \%$ & $42.3 \%$ \\
\hline Almaguer & $94.8 \%$ & $24.0 \%$ & $29.9 \%$ \\
\hline La Sierra & $89.6 \%$ & $50.4 \%$ & $56.3 \%$ \\
\hline La Vega & $93.8 \%$ & $45.5 \%$ & $48.9 \%$ \\
\hline Rosas & $86.9 \%$ & $34.4 \%$ & $41.6 \%$ \\
\hline Sotará & $94.3 \%$ & $35.9 \%$ & $37.3 \%$ \\
\hline
\end{tabular}

Fuente: Elaboración de IEI a partir de datos proporcionados por el Departamento Administrativo Nacional de Estadística DANE (Censo 2005) 